\title{
Predictors of early and medium-term outcome of 200 consecutive aortic valve and root repairs
}

\author{
Marek J. Jasinski, MD, PhD, Radoslaw Gocol, MD, Marcin Malinowski, MD, Damian Hudziak, MD,
} Piotr Duraj, MD, and Marek A. Deja, MD, PhD

\begin{abstract}
Objectives: Advantages of aortic valve repair and root reconstruction include maintenance of natural valve hemodynamic parameters and avoidance of prosthetic valve-related complications. However, general acceptance of valve reconstruction may be limited by paucity of long-term follow-up data from only a few centers. This report is intended to supplement existing outcome information for aortic valve repair.
\end{abstract}

Methods: Between 2003 and 2013, 200 consecutive patients (149 men, 51 women; mean age, 52.1 years) with significant aortic regurgitation and aortic root enlargement underwent aortic valve repair and associated root reconstruction. The same prospective selection criteria and systematic valve repair approaches were followed throughout the study. Root management consisted of either root remodeling or reimplantation with Dacron prostheses. Kaplan-Meier techniques were used to assess major end points of all-cause mortality, reoperation, and repair failure. Univariable log-rank testing was used to identify associations between risk factors and major events.

Results: Early mortality was 2\% (4 patients), and early repair failure was 3\% (6 patients). New York Heart Association functional class was found to be a risk factor for early mortality and morbidity (odds ratio, 3.3; $P=.03$ ), whereas crossclamp time and cardiopulmonary time were risk factors for early mortality (odds ratio, $1.04 ; 95 \%$ confidence interval, $1-1.07 ; P=.01$ and odds ratio, $1.02 ; 95 \%$ confidence interval, $1-1.03 ; P=.02$ ), respectively. Survival at a mean follow-up of $48.6 \pm 34.3$ months (median follow-up, 43.6 months; range, 17.8-78 months) was $94 \%$, with a freedom from reoperation of $91 \%$. Univariable risk factors for mortality were preoperative New York Heart Association functional class and requirement for root replacement. Repair failure and reoperation were associated with bicuspid valve anatomy, subcommissural annuloplasty, and complex leaflet repair. Freedom from repair failure was associated with aortic reimplantation.

Conclusions: Data from a prospective cohort of patients undergoing aortic valve repair and root reconstruction reinforce the satisfactory medium-term results obtained with valve reconstruction. Further analysis of these patient outcomes is necessary to draw definitive conclusions on operative techniques. (J Thorac Cardiovasc Surg 2015;149:123-9)

See related commentary on pages 129-30.

Interest in aortic valve repair during aortic root reconstruction is increasing, and valve-sparing operations, as introduced by David and colleagues, ${ }^{1,2}$ Yacoub and colleagues, ${ }^{3}$ and others, ${ }^{4}$ are being more commonly applied. Leaflet repair techniques, such as central leaflet plication, are becoming standardized ${ }^{5-8}$ and have contributed significantly to improving results. Other

\footnotetext{
From the Department of Cardiac Surgery, Medical University of Silesia, School of Medicine, Katowice, Poland.

Disclosures: Authors have nothing to disclose with regard to commercial support.

Read at The American Association for Thoracic Surgery Aortic Symposium 2014,

New York, New York, April 24-25, 2014

Received for publication June 18, 2014; revisions received Aug 6, 2014; accepted for publication Aug 18, 2014; available ahead of print Oct 13, 2014.

Address for reprints: Marek J. Jasinski, MD, PhD, Department of Cardiac Surgery, Medical University of Silesia, Ziolowa 47, 40-635 Katowice, Poland (E-mail: marekjas@poczta.onet.pl).

$0022-5223 / \$ 36.00$

Copyright (c) 2015 by The American Association for Thoracic Surgery

http://dx.doi.org/10.1016/j.jtcvs.2014.08.057
}

important developments include a classification of aortic regurgitation (AR), ${ }^{9,10}$ echocardiographic standardization, ${ }^{11}$ and a better understanding of bicuspid valve anatomy. ${ }^{12}$ Nonetheless, application of aortic valve repair is lagging. One potential cause of individual surgeon reluctance could be the still limited amount of long-term data that have been generated-and those data only in a few centers. The purpose of our study was to examine a single-center experience with aortic valve repair over 10 years to further clarify future application of aortic valve and root reconstruction.

\section{METHODS \\ Patient Population}

Two hundred consecutive patients undergoing aortic-valve-sparing surgery for chronic AR and/or associated root aneurysm from 2003 to 2013 were enrolled prospectively into the study. Only emergent patients were excluded. All patients without significant preoperative stenosis or poor leaflet tissue quality in the form of large areas of fibrosis, calcifications, and restriction as well as large fenestrations precluding aortic repair were preselected for repair/sparing procedure. They constitute one-third of all patients with root procedures. Preoperative transthoracic echocardiographic and transesophageal echocardiographic examinations 


\section{Abbreviations and Acronyms \\ $\mathrm{AR}=$ aortic regurgitation \\ NYHA $=$ New York Heart Association \\ STJ = siontubular junction \\ STS = Society of Thoracic Surgeons \\ VAJ $=$ ventriculoaortic junction}

were performed according to a defined protocol. The type of AR was systematically described, patients suitable for repair were identified, and surgical procedures were performed according to a consistent approach. Operative characteristics, as well as early postoperative outcomes, were recorded prospectively using a preestablished data set.

\section{Echocardiography and Patient Selection}

Transthoracic echocardiograms were obtained preoperatively, and then at 1 month following surgery. Subsequently, transthoracic echocardiograms were performed at 1 year according to guidelines published by the American Society of Echocardiography, Society of Cardiovascular Anesthesiologists, and European Society of Echocardiography. ${ }^{11}$ A thorough transesophageal echocardiographic examination was performed after induction of general anesthesia (before cardiopulmonary bypass), and then repeated at the end of the procedure. Required echocardiographic views (parasternal long axis and apical 4 and 5 chamber) with prespecified 2-dimensional cine loops were recorded, as were M-mode and Doppler data.

Patients were selected for aortic valve repair on the basis of echocardiographic findings, taking into account magnitude and character of AR, occurrence and location of leaflet prolapse, direction of the resulting AR jet, specific bicuspid anatomy, pliability/calcification of leaflets, annular size, sinotubular junction (STJ) dimensions, and aortic diameters. Aortic root dilatation was defined as significant at a sinus diameter in diastole measured above $4.5 \mathrm{~cm}$ in bicuspid and $5.0 \mathrm{~cm}$ in tricuspid anatomy, according to current recommendations. ${ }^{13}$

\section{Surgical Management}

All operations were performed through a median sternotomy, with standard cardiopulmonary bypass, in normothermia, with cannulation of the ascending or arch aorta and right atrium, and superior pulmonary vein venting. Myocardial protection was accomplished with anterograde cold blood cardioplegia and maintained with anterograde direct coronary reinfusion every 20 minutes. The ascending aorta was opened transversely, $1.5 \mathrm{~cm}$ above the tops of the commissures. For valve assessment, 3 stay sutures of 4-0 Prolene (Ethicon Inc, Somerville, NJ), were placed above the highest point of each commissure and positioned under tension. First, effective height of each leaflet was evaluated, ${ }^{14,15}$ as were central leaflet coaptation and individual leaflet prolapse. Second, the relative lengths of leaflet free margins were assessed with the Frater technique ${ }^{16}$; that is, suturing 3 noduli arantii together and identifying leaflets with disparately stretched, elongated segments producing prolapse. ${ }^{17-19}$

Type of repair was defined by the functional classification of El Khoury and colleagues. ${ }^{9}$ Morphologic criteria were added to specify groups of different surgical techniques. Sizes of aortic root in those groups are presented in Table 1.

\section{Type 1: Functional Aortic Annulus Enlargement Causing Central AR}

STJ and aortic enlargement. STJ remodeling was performed with the size of aortic prosthetic graft equal to ventriculoaortic junction
(VAJ) diameter. The anastomosis between root and the Dacron graft involved equal spacing between commissures.

STJ and sinuses of valsalva enlargement. Root remodeling was performed with separate sinuses replacement. Aortic prosthetic graft size was selected to be equal to VAJ diameter, which per definition ought to be $28 \mathrm{~mm}$ or less.

VAJ enlargement. Subcommissural annuloplasty was performed with 2-0 braided sutures with pledgets, including the middle third of the subcommissural triangles.

STJ, aortic root, and VAJ enlargement. Initially, David I valve reimplantation was employed, with a straight Dacron graft sized 2-4 mm larger that the desired STJ, measured over a Freestyle sizer (Metronic, Minneapolis, Minn), to produce satisfactory leaflet apposition. Since 2009 a modified reimplantation technique was employed, with a Valsalva conduit (Gelweave Valsalva; Vascutek, Inchinnan, Scotland) reproducing different shape and size of aortic root. Dacron prosthesis size was based on the height of commissures being the same as diameter in Valsalva conduit, with the nonleft coronary commissure chosen as the point of reference. During the reimplantation procedures, 10 to 12 2-0 pledgeted horizontal mattress sutures formed a proximal suture line at the ventriculoaortic junction, and a second outflow line was created with 3 running 4-0 Prolene sutures, starting from nadirs of each neosinus up to the highest commissural fixation.

\section{Type 2: Leaflet Prolapse and Eccentric AR}

With leaflet prolapse, 2 techniques were chosen: 7-0 Gore-Tex (W. L. Gore \& Associates, Inc, Flagstaff, Ariz) free edge stabilization and leaflet plication. The first technique began with suturing the Gore-Tex suture to the aorta at the commissure of the prolapsing leaflet, and then running a locking stitch along the free edge, referencing the length reduction required to the normal adjacent leaflet. Leaflet plication relied on free margin length assessment, and excess and prolapsing leaflet tissue was plicated centrally with 7-0 Prolene. ${ }^{16}$ Complex repair was defined as application of $>1$ techniques for leaflet management.

\section{Bicuspid Valve Disease}

Usually subcommissural annuloplasty was performed combined with raphe excision and autologous pericardial patch reconstruction. Gore-Tex leaflet stabilization or leaflet plication was added as necessary to correct prolapse, ${ }^{17}$ and additional root stabilization was performed with a remodeling straight aortic graft (Figure 1).

After aortic valve repair, the height of coaptation was considered acceptable if it was $\geq 4 \mathrm{~mm}$ on transesophageal echocardiography. Mild regurgitation (grade 1) was defined by vena contracta $<3 \mathrm{~mm}$, central jet with ratio to left ventricular outflow tract width of below $25 \%$, and normal flow pattern in descending aorta. Moderate residual regurgitation (grade 2) was diagnosed in presence of vena contracta of 3 to $6 \mathrm{~mm}$ and jet to left ventricular outflow tract ratio between $25 \%$ and $65 \%$. These could be accompanied by some degree of diastolic flow reversal in descending aorta but with end-diastolic velocity lower than $20 \mathrm{~cm} / \mathrm{sec}$. Higher values of the listed parameters would indicate severe residual regurgitation (grade 3). Finally, transvalvular gradients were determined with continuous wave Doppler.

\section{Data Acquisition and Analysis}

Baseline demographic, clinical, and echocardiographic data were recorded prospectively. Operative and follow-up data subsequently were collected directly and by review of patient records. As a part of the prospective study, all patients were scheduled for clinical and echocardiographic follow-up at 1 month and at 6 months to 1 year. All 200 patients operated between 2003 and 2013 were identified and included in the follow-up study. Follow-up data also were confirmed through the national registry, and $100 \%$ completeness of primary end point data could be 
TABLE 1. Echocardiographic data, preoperative data, and postoperative outcomes

\begin{tabular}{|c|c|c|}
\hline $\begin{array}{c}\text { Echocardiographic parameters/ } \\
\text { type of repair }\end{array}$ & Before & $\begin{array}{l}1 \mathrm{y} \text { after } \\
\text { operation }\end{array}$ \\
\hline \multicolumn{3}{|l|}{ Perioperative: postoperative vs preoperative } \\
\hline $\begin{array}{l}\text { Aortic annulus (ventriculoaortic } \\
\text { junction), mm }\end{array}$ & & - \\
\hline $\begin{array}{l}\text { Sinotubular junction and root } \\
\text { remodeling }\end{array}$ & $26.9 \pm 3.5$ & $25.9 \pm 3.6^{*}$ \\
\hline Valve reimplantation & $27.7 \pm 4.1$ & $24.8 \pm 2.7 \dagger$ \\
\hline Annuloplasty & $27.5 \pm 4.3$ & $26 \pm 4.6$ \\
\hline Bicuspid & $27.1 \pm 3.8$ & $25.3 \pm 3.7^{*}$ \\
\hline \multicolumn{3}{|l|}{ Aortic root, $\mathrm{mm}$} \\
\hline $\begin{array}{l}\text { Sinotubular junction and root } \\
\text { remodeling }\end{array}$ & $40.8(5.6)$ & $37.5(5.4) \ddagger$ \\
\hline Valve reimplantation & $46.9 \pm 3.7$ & $38.4 \pm 3.7 \S$ \\
\hline Annuloplasty & $38.8 \pm 4.1$ & $35.1 \pm 3.1$ \\
\hline Bicuspid & $40.6 \pm 4.7$ & $38 \pm 3.5 \|$ \\
\hline \multicolumn{3}{|l|}{ Aortic sinotubular junction, mm } \\
\hline $\begin{array}{l}\text { Sinotubular junction and root } \\
\text { remodeling }\end{array}$ & $33.1 \pm 5.0$ & $30 \pm 4.2$ \\
\hline Valve reimplantation & $40.4 \pm 7.5$ & $29.9 \pm 4.3 \pi$ \\
\hline Annuloplasty & $32.7 \pm 4.1$ & $27.8 \pm 3.1$ \\
\hline Bicuspid & $34.4 \pm 4.7$ & $29.4 \pm 3.5 \#$ \\
\hline End diastolic volume, $\mathrm{mL}$ & \multicolumn{2}{|c|}{$197.2 \pm 80.5156 .8 \pm 47.4^{* * *}$} \\
\hline Ejection fraction, $\%$ & $53.8 \pm 8$ & $56 \pm 11$ \\
\hline \multicolumn{3}{|l|}{ Preoperative/postoperative } \\
\hline Age, y & \multicolumn{2}{|c|}{$52.1 \pm 17.5$} \\
\hline Male gender, $\%$ & \multicolumn{2}{|c|}{75} \\
\hline $\begin{array}{l}\text { New York Heart Association } \\
\text { functional class III-IV, \% }\end{array}$ & \multicolumn{2}{|c|}{16} \\
\hline Graft size, $\mathrm{mm}$ & \multicolumn{2}{|c|}{$28 \pm 2.6$} \\
\hline Cross clamp time, $\min$ & \multicolumn{2}{|c|}{$84.7 \pm 41.9$} \\
\hline $\begin{array}{l}\text { Temperature on cardiopulmonary } \\
\text { bypass, }{ }^{\circ} \mathrm{C}\end{array}$ & \multicolumn{2}{|c|}{$34.3 \pm 4.3$} \\
\hline Bypass time, min & \multicolumn{2}{|c|}{$120.7 \pm 61.7$} \\
\hline Early mortality, \% & \multicolumn{2}{|c|}{ (4)- $2 \%$} \\
\hline $\begin{array}{l}\text { Early conversion to aortic valve } \\
\text { repair, \% }\end{array}$ & \multicolumn{2}{|c|}{$(6)-3 \%$} \\
\hline Reoperation for bleeding, $\%$ & \multicolumn{2}{|c|}{$(10)-5 \%$} \\
\hline Intra-aortic balloon pump & \multicolumn{2}{|c|}{$(8)-4 \%$} \\
\hline Low cardiac output & \multicolumn{2}{|c|}{ (3)- $-1.5 \%$} \\
\hline Ventilator $>48 \mathrm{~h}$ & \multicolumn{2}{|c|}{$(6)-3 \%$} \\
\hline Dialysis dependent renal failure & \multicolumn{2}{|c|}{$(2)-1 \%$} \\
\hline Deep sternal wound infection & \multicolumn{2}{|c|}{$(1)-0.5 \%$} \\
\hline
\end{tabular}

Values are presented as mean \pm standard deviation. *Comparison between preoperative and postoperative parameters. $\dagger P=.006 . \ddagger P=.037 . \S P=.001 . \| P=.004$. q $P=.009 . \# P<.004 . * * P=.002$

achieved. For the prediction of various events, unadjusted operative mortality and 7 morbidity-related end points were evaluated, according to the 2008 Society of Thoracic Surgeons (STS) valve model and STS definitions. ${ }^{20}$

To determine prognostic factors for development of valve-related events and long-term survival, a list of potential preoperative and perioperative risk factors was developed, including baseline characteristics, different techniques of surgical management, and perioperative operative data. Standard STS variables were included as baseline data: age, gender, hypertension, dyslipidemia, renal failure, endocarditis, chronic obstructive lung disease, previous operation, congestive heart failure (New York Heart
Association [NYHA] functional class), ejection fraction, status of presentation, concomitant operation (coronary artery bypass graft or mitral/tricuspid valve procedures), including different techniques of surgical management and perioperative data. Candidate covariates then were related to all end points of the study, including mortality, repair failure defined as either valve-related reoperations or severe $\mathrm{AR}$, and reoperation, using univariable Kaplan-Meier techniques. Multivariable analysis was not possible because of the low event rate, so for statistical analyses, Kaplan-Meier time-to-event curves were generated, and univariable log rank tests were employed to compare outcomes relative to subgroups. Mann-Whitney rank sum tests were used to evaluate continuous data All analyses were performed using Sigma Plot 10.0 (Systat Software Inc, San Jose, Calif). This study was approved by the ethics committee of the Medical University of Silesia as statuatory project KNW-2-136-10.

\section{RESULTS \\ Early Outcomes}

Baseline characteristics for the 200 patients undergoing aortic valve repair included mean age $52.1 \pm 17.5$ years, male gender (75\%); NYHA functional class III or IV (32), mean creatinine $1.19 \pm 1.5 \mathrm{mg} / \mathrm{dL}$, mean body weight 83.2 \pm 9.9 , and mean height $176.1 \pm 9.9 \mathrm{~cm}$. Comorbidities included smoking (46\%), hypertension (63\%), hyperlipidemia $(36 \%)$, and diabetes $(43 \%)$. Surgical techniques applied according to functional and anatomic classification (see Methods section) included STJ and root enlargement (aorta replacement plus STJ remodeling in 30 patients or root remodeling in 54 patients); STJ, VAJ, and root enlargement (aortic valve reimplantation in 56 patients and Valsalva graft in 35 patients); VAJ enlargement (subcomissural annuloplasty in 104 patients and external annuloplasty in 14); and leaflet prolapse (plication/complex repair with resection/Gore-Tex reinforcement in 51, 26, and 23 patients, respectively). Cusp anatomy was tricuspid in 140 patients and bicuspid in 60 patients. Leaflet repair consisted of free-edge remodeling with 7-0 Gore-Tex in 26 patients with and without resection, leaflet plication in 51 patients, and triangular resection with or without patch in 26 patients. When necessary, leaflet shaving was added in 26 patients. Techniques applied for annular stabilization were subcommissural annuloplasty in 104 patients, reimplantation into the aortic graft in 56 patients, and external annuloplasty (ie, cutting of tube graft sutured with interrupted pledget) in 14 patients. Root management was performed as reimplantation in 56 patients and remodeling in 54 patients. The ascending aorta was replaced in 140 patients. Twenty patients had concomitant coronary artery bypass graft, 18 patients underwent mitral procedures, and 7 patients had tricuspid valve surgery. In-hospital mortality was $2 \%(n=4)$. Causes were multiorgan failure $(n=2)$ and congestive heart failure $(n=2)$.

Operative data are given in Table 1. Mean cardiac ischemic time was 85.9 minutes, whereas average cardiopulmonary bypass time was 123.6 minutes. There were 6 procedural conversions or reoperations during the same admission $(3 \%)$. These included root remodeling 
TABLE 2. Risk factors for early mortality and unadjusted operative mortality (UOM) and unadjusted mortality and morbidity

\begin{tabular}{|c|c|c|c|c|}
\hline \multirow[b]{2}{*}{ Variable } & \multicolumn{2}{|c|}{ Risk of UOM and morbidity } & \multicolumn{2}{|c|}{ Risk of early mortality } \\
\hline & OR $(95 \%$ CI $)$ & $P$ value & OR $(95 \%$ CI $)$ & $P$ value \\
\hline Age & $1.01(0.99-1.05)$ & .28 & $0.98(0.93-1.04)$ & .66 \\
\hline Crossclamp time & $1.01(1-1.02)^{*}$ & $.06^{*}$ & $1.04(11.07)^{*}$ & $.01 \dagger$ \\
\hline Bypass time & $1.01(0.99-1.01)^{*}$ & $.07 *$ & $1.01(1-1.03)^{*}$ & $.02 \dagger$ \\
\hline Left ventricular ejection fraction & $0.96(0.9-1.01)$ & .09 & $0.97(0.87-1.08)$ & .6 \\
\hline Urgent operation & $1.1(0.3-3.5)$ & .9 & $1.5(0.1-15.4)$ & .7 \\
\hline New York Heart Association functional class $\geq$ III & $3.3(1.1-9.8) \dagger$ & $.034 \dagger$ & $7.1(0.94-53.6) *$ & $.057 *$ \\
\hline
\end{tabular}

$O R$, Odds ratio; $C I$, confidence interval; $U O M$, unadjusted operative mortality. ${ }^{*}$ Trends. †Univariable risk factor analysis suggested significance to variables.

failure in 1 patient, bicuspid aortic valve repair failure in 2 patients, and tricuspid prolapse treated with Gore-Tex remodeling in 2 patients, and valve reimplantation with bileaflet prolapse in 1 patients. Prosthetic valve replacements were performed in all cases, including Bentall operations in 2 patients. No deaths or any procedural complications occurred in patients undergoing conversion. NYHA functional class was found to be a risk factor for early mortality (ie, unadjusted operative mortality) and morbidity (odds ratio $[\mathrm{OR}], 3.3 ; P=.03$ ), whereas crossclamp time and cardiopulmonary time were risk factors for early mortality (OR, $1.04 ; 95 \%$ confidence interval, $1-1.07 ; P=.01$ and $\mathrm{OR}, 1.02 ; 95 \%$ confidence interval, $1-1.03 ; P=.02$ ), respectively (Table 2). Postoperative and echocardiographic outcomes also are presented in Table 1. Early after repair, the majority of patients $(\mathrm{n}=172 ; 91 \%)$, had none to mild AR, and only $8 \%$ had moderate residual leak. The decrease in end diastolic volume early after valve repair was clinically and statistically significant $(P=.04)$. Remodeling of the aortic root was significant, especially in reimplantation types of aortic sparing operations.

\section{Late Outcome}

Five patients died during follow-up. Overall survival at a mean $48.6 \pm 34.3$ months with median 43.6 months (1st and 3rd percentile: 17,78 ), was $94.0 \% \pm 1.9 \%$. One late death occurred 2 months after emergency redo surgery for Type B dissection. One was related to stroke 2 months postoperation and 3 were not cardiac-related. Seven patients developed moderate-to-severe AR. Overall 6-year freedom from reoperation was $90.4 \%$ and freedom from repair failure (AR grade $\geq 2$ or valve related redo operation) was $93.0 \% \pm 3.2 \%$. Eight patients required late reoperation. Two reoperations were not valve-related: acute dissection of aortic arch and descending aorta in 1 patient, and chronic dissection of descending aorta in a Marfan patient. Other reoperations were caused by either vascular septal defect at the level of perimembranous septum related to rupture of subcommissural annuloplasty or bicuspid aortic valve complex repair ( 2 patients had disruption after raphe excision, 2 patients experienced prolapsing conjoint leaflet after resection with patching and Gore-Tex stabilization and 1 by endocarditis). Mean time to reoperation was $30.6 \pm 31.9$ months (median, 9.1 months [1st and 3rd percentile: 2, 64]) and to valve-related reoperation $47.5 \pm 34.5$ months (median, 10 months [1st and 3rd percentile: 4,71$]$ ).

\section{Risk Factor Analysis}

In the medium-term analysis, no patients were lost to follow-up. Significant univariable risk factors (Table 3) were long-term mortality (ie, NYHA functional class, creatinine level $(P=.05)$, ejection fraction $(P=.05)$, and root replacement), reoperation (ie, complex leaflet repairs such as Gore-Tex leaflet edge remodeling and leaflet resection with or without patch leaflet), valve-related reoperation or AR recurrence (ie, bicuspid aortic valve, complex leaflet repairs, and repair without reimplantation). Adverse aortic events for composite end point (all previous) was NYHA functional class III to IV and complex leaflet repair.

\section{DISCUSSION}

The primary reason for transitioning to aortic valve repair is potentially lower incidence of valve-related complications, ${ }^{21,22}$ compared with prosthetic valve replacement. ${ }^{23}$ However aortic valve sparing surgery currently is applied in a minority of patients. ${ }^{24}$ One possible reason for slow adoption is the lack of a widely accepted systematic approach allowing for clearly reproducible results. In the 10-year experience we report here, El Khoury's surgical algorithm was applied consistently, and all patients were followed with defined protocols. The type of AR was classified $^{9}$ and was used to apply validated surgical techniques ${ }^{10}$ in an effort to better understand the subject. In this single-center prospective study, the feasibility of aortic valve repair with associated aortic root management was demonstrated, and the approach provided satisfactory long-term survival, freedom from reoperation, and valve repair stability.

Another reason for slow adoption may be the limited outcome data currently available to support valve reconstruction. Several centers recently have examined the detailed results of aortic repair, ${ }^{25-30}$ and our findings reinforce most of their conclusions. Over 8 years of 
TABLE 3. Risk factors for survival, reoperation, structural valve deterioration, and combined adverse aortic valve events

\begin{tabular}{|c|c|c|c|c|c|c|c|c|c|c|}
\hline \multirow[b]{2}{*}{ Variable } & \multicolumn{2}{|c|}{ Survival } & \multicolumn{2}{|c|}{ Reoperation } & \multicolumn{2}{|c|}{$\begin{array}{l}\text { Valve-related } \\
\text { reoperation }\end{array}$} & \multicolumn{2}{|c|}{$\begin{array}{l}\text { Structural valve } \\
\text { deterioration }\end{array}$} & \multicolumn{2}{|c|}{$\begin{array}{c}\text { Adverse aortic } \\
\text { events }\end{array}$} \\
\hline & $\begin{array}{c}\text { Log-rank } \\
\text { test statistic }\end{array}$ & $\begin{array}{c}P \\
\text { value }\end{array}$ & $\begin{array}{c}\text { Log-rank } \\
\text { test statistic }\end{array}$ & $\begin{array}{c}P \\
\text { value }\end{array}$ & $\begin{array}{c}\text { Log-rank } \\
\text { test statistic }\end{array}$ & $\begin{array}{c}P \\
\text { value }\end{array}$ & $\begin{array}{c}\text { Log-rank } \\
\text { test statistic }\end{array}$ & $\begin{array}{c}P \\
\text { value }\end{array}$ & $\begin{array}{c}\text { Log-rank } \\
\text { test statistic }\end{array}$ & $P$ value \\
\hline Urgent operation & 0.59 & .44 & 1.27 & .26 & 0.78 & .39 & 0.92 & .34 & 1.3 & .25 \\
\hline $\begin{array}{l}\text { New York Heart Association } \\
\quad \text { functional class } \geq \text { III }\end{array}$ & $35.8^{*}$ & $<.001^{*}$ & 0.04 & .85 & 0.54 & .46 & 0.98 & .32 & $15.0^{*}$ & $<.001 *$ \\
\hline Cusp plication & 1.17 & .28 & 0.0001 & .97 & 0.24 & .62 & 1.49 & .22 & 0.57 & .45 \\
\hline Subcommisural repair & 2.0 & .16 & $3.33 \dagger$ & $.068 \dagger$ & $4.2 *$ & $.04 *$ & 0.38 & .54 & 0.00 & .99 \\
\hline Bicuspid valve & $-3.13 \dagger$ & $.077 \dagger$ & 2.41 & .12 & $7.44 *$ & $.006^{*}$ & $12.16^{*}$ & $<.001 *$ & 0.66 & .41 \\
\hline Gore-Tex $\ddagger$ used & 0.04 & .84 & $13.84 *$ & $<.001^{*}$ & $7.23^{*}$ & $.007 *$ & $11.93 *$ & $<.001 *$ & $5.59 *$ & $.02 *$ \\
\hline $\begin{array}{l}\text { Complex repair: Resection }+ \\
\text { Gore-Tex }+\end{array}$ & 0.7 & .4 & $10.02 *$ & $.002^{*}$ & $16.92 *$ & $<.001^{*}$ & $18.02 *$ & $<.001 *$ & $6.12^{*}$ & $.01 *$ \\
\hline Patch & 0.22 & .64 & 0.24 & .62 & 0.17 & .68 & 2.3 & .13 & 0.57 & .45 \\
\hline Decalcification- Shaving & 0.45 & .5 & 0.43 & .5 & 0.29 & .59 & 0.47 & .49 & 0.99 & .32 \\
\hline Complex repair: Resection + patch & 1.42 & .23 & $3.12 \dagger$ & $.077 \dagger$ & $6.78^{*}$ & $.009 *$ & 6.38 & .01 & 0.91 & .34 \\
\hline Remodeling STJ & 1.8 & .18 & 0.08 & .78 & 0.05 & .83 & 0.33 & .57 & 0.36 & .55 \\
\hline Remodeling overall & 0.26 & .61 & 0.14 & .71 & 0.14 & .7 & 0.76 & .38 & 0.09 & .77 \\
\hline Reimplantation overall & 1.23 & .27 & 1.02 & .31 & 2.04 & .15 & $-3.63 \dagger$ & $.057 \dagger$ & 0.34 & .56 \\
\hline Root Replacement & $5.05^{*}$ & $.025 *$ & 1.52 & .22 & 2.55 & .11 & 0.57 & .45 & 0.29 & .59 \\
\hline $\mathrm{MV} / \mathrm{TV} /$ coronary artery bypass graft & 0.86 & .35 & 0.02 & .89 & 0.44 & .51 & 1.08 & .3 & 0.48 & .49 \\
\hline
\end{tabular}

STJ, Siontubular junction; $M V$, mitral valve repair; $T V$, tricuspid valve repair. *Univariable risk factor analysis suggested significance to variables. $\dagger$ Trends in those. $\ddagger \mathrm{W}$. L. Gore and Associates, Flagstaff, Ariz.

follow-up, the Brussels group ${ }^{10}$ found an overall survival of $87 \%$, freedom from reoperation of $91 \%$, and freedom from recurrent AR of $79 \%$. The series from Aicher et $\mathrm{al}^{21}$ showed similar results, for both tricuspid and bicuspid valves. Our study correlates well with both of these experiences in that the majority of patients had none to mild AR early after repair, and a minority had moderate residual leak. At

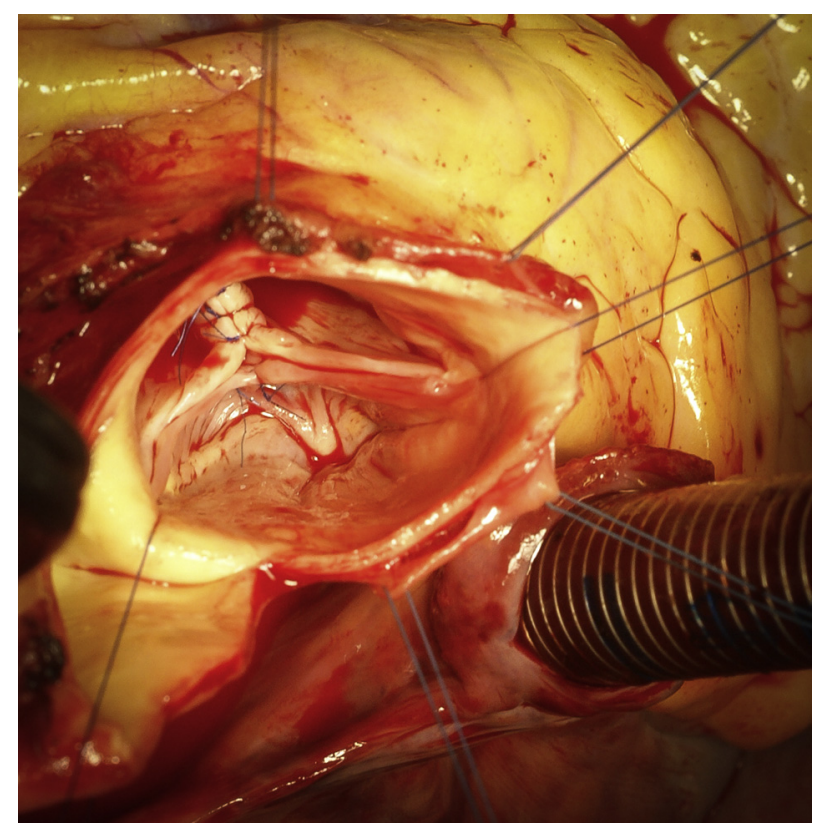

FIGURE 1. Bicuspid aortic valve repair: Leaflet plication and external annuloplasty. follow-up, these results were stable and largely sustained long-term, with acceptable rates of survival, reoperation, and recurrent AI (Table 3). Repair efficacy also was illustrated by decreasing end diastolic volume and improving ejection fraction, findings indicating ventricular recovery from volume overload (Table 2).

An important risk factor for early and late mortality was advanced heart failure (adverse events OR, 15) (Table 3). This finding may reflect the heterogeneous population in this series, with a significant proportion of higher-risk patients. Given the prospective nature of the study design, patients were preselected only on the basis of echocardiographic analysis, and patients with severe congestive heart failure symptoms were included in the repair group. One recent study ${ }^{25}$ suggests that aortic valve sparing can be performed with no higher mortality in high-risk, as well as low-risk patients, and our experience supports that perspective.

Techniques of leaflet repair are still developing, and our findings support previous studies showing the efficacy of central leaflet plication for correction of prolapse. Conversely, Gore-Tex free margin reinforcement did not fare well, although in our analysis this variable could be a surrogate for worse baseline leaflet disease illustrated by complexity of leaflet repair. It is confirmed by the findings that the strongest predictor of adverse events, redo operations, and repair failure (composite end point) was a complex leaflet repair consisting of $>1$ repair technique deemed necessary (additional resection) (OR, 6.12) (Table 3). Commissural suspension or the Trusler stitch 
also probably should be avoided because of late disruption of the high-stress regions of commissural leaflets. ${ }^{31}$ Thus, leaflet plication probably should be the first choice for prolapse correction, and in fact, availability of this technique is a major enabler for expansion of aortic valve reconstruction.

Root replacement during valve repair was found to be a risk factor in our experience, although strictly limited to the early postoperative period (OR, 5.05) (Table 3) This finding may be related to higher complexity of this operation and longer crossclamp and bypass time required, which were found to be negative predictors of early mortality A concept also exists that severe valve pathology portends a less good result with reimplantation, although this is controversial. Interestingly, after a successful David procedure in this series there were no late events, confirming its durability and good prognostic effect (Table 3). David and colleagues ${ }^{2}$ found $95 \%$ freedom from severe valve dysfunction at 10 years, and Shrestha and colleagues ${ }^{26}$ described an $85 \%$ freedom from reoperation. Our results confirm few late cardiac related events after a reimplantation-type aortic valve sparing operation, although complexity and poorer applicability in severe valve dysfunction may be problematic.

The bicuspid valve has been found a predictor for valve-related redo operation in our series (OR, 7.44) (Table 3), with the cofactor being subcomissural annuloplasty. Boodhwani and colleagues ${ }^{32}$ found similar long-term results between bicuspid and tricuspid aortic valve repair, and Kerchove and colleagues ${ }^{33}$ confirmed adequate stability after bicuspid valve repair, although with a higher late failure rate after subcomissural stabilization.

There are certain limitations of our study. There are different techniques of leaflet repair, root management, and annular stabilization for varying degrees of regurgitation and different pathology. Secondly, the results, albeit midterm only, although being acceptable do not yet support broader application of aortic valve repair. Until we have 15 years' follow-up results, ideally in randomized with aortic valve replacement with or without aorta replacement, we still do not know the ideal treatment for these patients.

\section{CONCLUSIONS}

A medium-term follow-up of 4 years of a prospectively analyzed cohort of patients suggests that aortic valve repair and associated aortic root reconstruction can be performed with satisfactory results and good early and medium-term durability. Further analysis of these patients' outcomes is necessary to draw definitive conclusions on operative techniques; however, complex leaflet repair confers the least durability in the medium term.

\section{References}

1. David TE, Feindel CM. An aortic valve-sparing operation for patients with aortic incompetence and aneurysm of the ascending aorta. J Thorac Cardiovasc Surg. 1992;103:617-22.

2. David TE, Feindel CM, Webb GD, Colman JM, Armstrong S, Maganti M, et al. Aortic valve preservation in patients with aortic root aneurysm; results of the reimplantation technique. Ann Thorac Surg. 2007;83:S732-5.

3. Yacoob MH, Gehle P, Chandrasekaran V, Birks E, Child A, Radley-Smith R, et al. Late results of a valve sparing operation in patients with aneurysm of aorta and root. J Thorac Cardiovasc Surg. 1998:115:1080-90.

4. Schäfers H-J, Kunihara T, Fries P, Brittner B, Aicher D. Valve-preserving root replacement in bicuspid aortic valves. J Thorac Cardiovasc Surg. 2010;140: S36-40.

5. Schäfers H-J. Reconstruction of the bicuspid aortic valve. Op Tech Thorac Cardiovasc Surg. 2007;12:2-13.

6. Aicher D, Langer F, Adam O, Tscholl D, Jausberg H, Schafers HJ, et al. Cusp repair in aortic valve reconstruction: does the technique affect stability? J Thorac Cardiovasc Surg. 2007;134:1533-9.

7. Chiappini B, Pouleur A-C, Noirhomme P, De Kerchove L, El Khoury G. Repair of trileaflet aortic valve prolapse: mid-term outcome in patients with normal aortic root morphology. Interact Cardiovasc Thorac Surg. 2007;6:56-9.

8. Price J, De Kerchove L, El Khoury G. Aortic valve repair for leaflet prolapse. Sem Thoracic and Cardiovasc Surg. 2011;23:149-51.

9. El Khoury G, Glineur D, Rubay J, Verhelst R, dAcoz Y, Poncelet A, et al. Functional classification of aortic root/valve abnormalities and their correlation with etiologies and surgical procedures. Curr Opin Cardiol. 2005;20115-21.

10. Boodhwani M, De Kerchove L, Glineur D, Poncelet A, Rubay J, Astarci P, et al. Repair-orientated classification of aortic insufficiency: impact on surgical techniques and clinical outcomes. J Thorac Cardiovasc Surg. 2009; 137:286-94.

11. Vahanian A, Alfieri O, Andreotti F, Antunes MJ, Barón-Esquivias G, Baumgartner H, et al. The Joint Task Force on the management of valvular heart disease of the ESC and EACTS. Guidelines on the management of valvular heart disease. Eur J Cardiothorac Surg. 2012;42(Suppl):S1-44.

12. Sievers HH, Schmidtke C. A classification system for the bicuspid aortic valve from 304 surgical specimens. J Thorac Cardiovasc Surg. 2007; 133:1226-33.

13. 2006 Writing Committee Members. 2008 Focused update incorporated into the ACC/AHA 2006 Guidelines for the management of patients with valvular heart disease. Circulation. 2008;118:e523-661.

14. Schäfers H-J, Bierbach B, Aicher D. A new approach to the assessment of aortic cusp geometry. J Thorac Cardiovasc Surg. 2006;132:436-8.

15. Aicher D, Langer F, Adam O. Bicuspid valve repair. Circulation. 2011;123:178-85.

16. Langer F, Greater T, Nikolaudakis N, Aicher D, Wendler O, Schafers HJ. Valvepreserving aortic replacement: does the additional repair of leaflets prolapse adversely affect the results? J Thorac Cardiovasc Surg. 2001;122:270-7.

17. De Kerchove L, Boodhwani M, Glineur D, Poncelet A, Rubay J, Astarci P, et al. Cusp prolapse repair in trileaflet aortic valves: free margin plication and free margin resuspension techniques. Ann Thorac Surg. 2009;88:455-61.

18. De Kerchove L, Glineur D, Poncelet A, et al. Repair of aortic leaflet prolapse, a ten year experience. Eur J Cardiothorac Surg. 2008;34:780-4.

19. Boodhwani M, De Kerchove L, Glineur D, Watremez CH, Vanoverschelde J-L, Noirhomme P, et al. Assessment and repair of aortic valve cusp prolapse: implications for valve-sparing procedures. J Thorac Cardiovasc Surg. 2011; 141:917-25.

20. O'Brien SM, Shahian DM, Filardo G. The STS 2008 cardiac surgery risk score models: part 2 isolated valve surgery. Ann Thorac Surg. 2009;88:23-42.

21. Aicher D, Fries R, Rodionycheva S, Schmidt K, Langer F, Schafers HJ, et al Aortic valve repair leads to a low incidence of valve-related complications. Eur J Cardiothorac Surg. 2010;37:127-32.

22. Price J, De Kerchove L, Glineur D, et al. Risk of valve-related events after aortic valve repair. Ann Thorac Surg. 2013;95:606-13.

23. Hammermeister K, Sethi GK, Henderson WH, et al. Outcomes 15 years after valve replacement with a mechanical versus a bioprosthetic valve: final report of the Veterans Affairs randomized trial. J Am Coll Cardiol. 2000;36:1152-8.

24. Caceres M, Ma Y, Rankin JS, Saha-Chaudhuri P, Englum B, Gammie J, et al. Mortality characteristics of aortic root surgery in North America. Eur J Carediothorac Surg. March 17, 2014 [Epub ahead of print].

25. Badiu C, Bleiziffer S, Eichinger W, Zaimova E, Hutter A, Mazzitelli D, et al. Are bicuspid aortic valves a limitation for aortic valve repair? Eur J Cardiothorac Surg. 2011;40:1097-104. 
26. Shrestha M, Pichlmaier M, Baraki H, et al. Long term results after aortic valvesparing operation. Eur J Cardiothorac Surg. 2012;42:56-62.

27. Leontyev S, Trommer C, Subramanian S, Lehman S, Dmitreva, Misfeld M, et al. The outcome after aortic valve-sparing (David) operation in 179 patients: a single- center experience. Eur J Cardiothorac Surg. 2012;42: 261-7.

28. Cameron DE, Alejo DE, Patel ND, Nwakamma L, Weiss E, Vricella L, et al. Aortic root replacement in 372 Marfan patients: evolution of operative repair over 30 Years. Ann Thorac Surg. 2009;87:1344-50.

29. Kvitting JE, Kari FA, Fischbein MP, Liang D, Beraud A-M. David valve-sparing aortic root replacement: equivalent mid-term outcome for different valve types with or without connective tissue disorder. J Thorac Cardiovasc Surg. 2013; 145:117-27.
30. Urbanski P, Zhan X, Hijazi H, Zacher M, Diegeler A. Valve-sparing aortic root repair without down-sizing of the annulus. J Thorac Cardiovasc Surg. 2012;143:294-302.

31. Marom G, Haj-Ali R, Raanani E. A fluid-structure interaction model of the aortic valve with coaptation and compliant aortic root. Med Biol Eng Comput. 2012;50: 173-82.

32. Boodhwani M, de Kerchove L, Glineaur D, Rubay J, Vanoverschelde J-L, Noirhomme P, El Khoury G. Repair of regurgitant bicuspid aortic valves: a systemic approach. J Thorac Cardiovasc Surg. 2010;140:276-84.

33. De Kerchove L, Boodhwani M, Glineaur D, Vandyck M, Vanoverschelde J-L, E Khoury G, et al. Valve sparing root replacement with the reimplantation technique to increase the durability of bicuspid aortic valve repair. $J$ Thorac Cardiovasc Surg. 2011;142:1430-8.

\title{
EDITORIAL COMMENTARY
}

\section{Aortic valve repair: Easy and reproducible?}

\author{
Hans-Joachim Schäfers, MD
}

\section{See related article on pages 123-9.}

Aortic valve repair has made marked progress in the past 20 years. Initially started as a technique for valve-preserving aortic replacement primarily for patients with aortic dilatation and an absence of relevant cusp pathology, it has evolved to encompass both isolated cusp repair and combined root and cusp repair. Early morbidity and mortality have been low, ${ }^{1,2}$ and the risk of valve-related complications is lower than that generally seen after replacement. ${ }^{2}$ Aortic valve repair leads to excellent quality of life, ${ }^{3}$ and there is the beginning of evidence that it may also improve survival. ${ }^{4}$

Initially, few centers embarked on this new type of surgery; in Europe, it was mainly performed by the group from Brussels ${ }^{5}$ and my own group. ${ }^{6}$ With better understanding of the interaction of cusp and root geometry and refinement of techniques of cusp repair, the concept of aortic valve repair has been accepted and used successfully by other groups. ${ }^{7-10}$ The good early and midterm results of the series of Jasinski and colleagues ${ }^{11}$ published in this issue of the Journal of Thoracic and Cardiovascular Surgery emphasize

\footnotetext{
From the Department of Thoracic and Cardiovascular Surgery, Saarland University Medical Center, Homburg/Saar, Germany.

Disclosures: Author has nothing to disclose with regard to commercial support.

Received for publication Sept 12, 2014; accepted for publication Sept 12, 2014; available ahead of print Oct 7, 2014.

Address for reprints: Hans-Joachim Schäfers, MD, Department of Thoracic and Cardiovascular Surgery, University Hospitals, Kirrberger Strasse, 66421 Homburg/ Saar, Germany (E-mail: h-j.schaefers@uniklinikum-saarland.de).

J Thorac Cardiovasc Surg 2015;149:129-30

$0022-5223 / \$ 36.00$

Copyright $(2015$ by The American Association for Thoracic Surgery http://dx.doi.org/10.1016/j.jtcvs.2014.09.022
}

that this surgical approach is reproducible. In addition, Jasinski and colleagues ${ }^{11}$ found that repair failure was associated with bicuspid anatomy and complex cusp repair, whereas concomitant root replacement was associated with improved valve stability. Although the latter finding is in concord with other published data, Jasinski and colleagues ${ }^{11}$ also saw an increased late mortality associated with root replacement, which offsets its potential stability advantage.

In the analysis of their experience, Jasinski and colleagues ${ }^{11}$ also found 2 specific aspects that confirm previous publications and experience: (1) subannular plication sutures do not result in adequate repair stability, at least in the case of bicuspid aortic valves, and (2) repair of cusp prolapse by plication of redundant cusp tissue seems to yield more reproducible and stable results than does the application of a running polytetrafluoroethylene suture to the cusp margin. The observation on subannular sutures has been made previously by others ${ }^{12,13}$; in fact, in my group's experience these sutures have been a potential predictor of valve failure. ${ }^{12}$ The stability of cusp plication in prolapse repair is in concord with my own group's total experience in more than 1600 patients.

Is aortic valve repair therefore easy with most of the techniques described, and should all risk factors for failure be avoided? The results of Jasinski and colleagues ${ }^{11}$ are difficult to interpret because of the inhomogeneity of the patient population studied and the variety of techniques used. The data thus may be difficult to reproduce by others if they attempt to base their clinical practice on the information of the publication. First, Jasinski and colleagues ${ }^{11}$ used a classification that relates echocardiographic information to the mechanism of aortic regurgitation and suggests a principal type of surgery on this basis. ${ }^{14}$ This classification does not 